\title{
Application of Politeness Strategies and Maxims in Fortress Besieged
}

\author{
Y.H. DU \\ Guangzhou Vocational College of Science and Technology, Guangzhou, Guangdong, China
}

\begin{abstract}
As a pervasive phenomenon in human communication, politeness has been one of the key issues discussed by pragmatists. Through the analysis of politeness strategies and maxims in Fortress Besieged by Chien Chung-shu, this thesis intends to show that people are likely to use vivid, pleasant and indirect expressions for something they think unpleasant or in embarrassing situations, to make their communications more enjoyable and relationship more harmonious.
\end{abstract}

KEYWORD: Politeness strategies; politeness maxims; Fortress Besieged

\section{INTRODUCTION}

Fortress Besieged, published in 1947, is widely regarded as one of the greatest works of the 20th century. It is a humorous tale of the Chinese middleclass in the 1940s. It depicts the hero's vagrant life experience in humorous and ironic ways. The author aims to expose that life is just like a big besieged fortress, whose residents get entangled in endless pressures and ties. For many years, a great deal of critics and researchers have done lots of researches on Fortress Besieged from different angles, which have mainly focused on its translation style, narrative art, theme, and comparison with other works, whereas with few being touched from the perspective of politeness strategies and principles.

Politeness is one of the guidelines for social interaction as well as a symbol of human civilization. According to Lakoff, politeness is "a system of interpersonal relations designed to facilitate interaction by minimizing the potential for conflict and confrontation inherent in all human interchange". (Lakoff 1990) Politeness here can be roughly defined as the realization of speech style and formality, which is meant to show respect for or consideration of others.

The face-saving act of politeness is associated with Brown and Levinson(1987), who divided face into positive and negative. "If a speaker says something that represents a threat to another individual's expectations regarding self-image, it's described as a face-threatening act." (FTA) (Yule 2000) Since nearly every speech act constitutes a threat to the positive and negative face of either of the two interactants, certain linguistic strategies must be chosen in order to mitigate the face-threatening power. That comes the face-saving act. (FSA) Brown and Levinson (1978)show us different ways a person can deal with a FTA. The choice of politeness depends on the speaker's judging the size of the FTA, which is assessed on the basis of the dimension of power, distance and imposition.

Leech's view of politeness includes a set of maxims, among which are (Leech, 1983) tact maxim, generosity maxim, approbation maxim, modesty maxim, agreement maxim and sympathy maxim. The general framework helps tell the crosscultural differences in the enactment of politeness. The tact maxim, for example, seems central to the western notions of politeness in that there is a routine mitigation of speech acts such as requests by offering choices. With an analysis of the application of politeness principles in Fortress Beseiged, this thesis shows that people tend to choose politeness strategies and maxims for interpersonal speech, aiming to earn recognition of others and lead to successful interpersonal exchanges.

\section{POLITENESS STRATEGIES IN FORTRESS BESIEGED}

\subsection{Positive Politeness and Negative Politeness}

\section{A: Miss Su B: Fang Hung-chien}

A: Never mind the calligraphy. What do you think of the poem? 
B: Could someone as ambitious as Wang Er-kai for high political office write good poetry? I'm not asking him for a job, and there's no obligation for me to flatter him.

B: Oh, terrific! This poem was cribbed.

B: At the very least it was borrowed a foreign loan. Mr. Tsao was quite right when he said it had the flavor of an ancient folk song. Remember, Miss Su?

Knowing that it's a poem done by Wang Er-kai, Fang Hung-chien called it "a bad one" and then "plagiarized", totally unaware of Miss Tang's frowning and shaking her head at him, threatening Miss Su's positive face wants desiring for others' appreciation and approval again and again. As a result, it ends in un-pleasure. (A: I don't like your cutting remarks. So Fang Hung-chien is the only intelligent person in the world.)

But while he found out that Miss Su was the actual author, Fang Hung-chien immediately adopted positive and negative strategies to soften his blow to Miss Su, considering his FTAs might have done harm to their consequent ties.

\section{A: Miss Su B: Fang Hung-chien}

B: Miss Su, did you get my letter?

A: Yes, I did. You are childish. I don't blame you. Don't I know your temperament?

B: You may be willing to forgive me, but I can't forgive myself.

A: Oh, is it worth getting so upset about such trivia? Tell me, do you really think that poem is good?

B: I just wish such a good poem hadn't been written by Wang Er-kai. It's too unfair!

B: Yours is more lively than the German poem. Because he knew that Miss Su had written the poem, Fang Hung-chien first flattered and then praised that it was more elastic than the German version. He met Miss Su's positive face wants, keeping her selfimage in his speech act in line with Miss Su's expectation. While such words as "you can forgive me, but I can't forgive myself" showed his respect for Miss Su's negative face wants by avoiding intruding her freedom of excusing him, but without an excuse for himself.

\subsection{Off-record}

\section{A: Chao Hsin-mei B: Fang Hung-chien}

A: The best man, a friend of Tsao Yuan-lang's, keeping following her and wouldn't let her leave his sight for a second. I could see he was very interested in her.

B: I don't care to hear about such people's affair. Don't talk to me about them.

A: We've been sitting here long enough. It is pretty windy now. Let's go back to the cabin and turn in. We'll be going ashore early tomorrow morning.

In such a case, after a realization of something should not have been mentioned (concerning seeing Miss Tang who had been pestered by the groomsman on the wedding of Miss Su), Chao Hsin-mei diverted to another topic to mitigate his unconscious damage to Fang Hung-chien's face, and never touched on the wedding again, which in return help him "achieve interpersonal rapport" (Li \& Ran 2014) with Hungchien by easing the embarrassment.

\section{POLITENESS MAXIMS IN FORTRESS BESIEGED}

\subsection{Tact Maxim}

\section{Dialogue 1}

\section{A: Fang Hung-chien $\quad$ B: Miss Su}

A: I'd better be going. This evening you still have to go out with your mother on a social engagement.

B: I don't have any engagement. That was just an excuse, because Hsin-mei was so rude to you. I don't want to make him any more arrogant.

\section{Dialogue 2}

\section{A: Miss Su B: Fang Hung-chien}

A: That girl is very capable for her age. She has a slew of boyfriends that she fools around with!

B: You were quite popular yourself in those days, but you always looked so arrogant. We could only admire you from a distance.

When Hsin-mei was little, he had a secret crush on Miss Su. He had taken Hung-chien as his love rival since his first sight of him, and wanted to overwhelm and scare off Hung-chien with his forbidding mannerism. In dialogue 1, being aware of Hsin-mei's rudeness to Hung-chien out of jealousy, Miss $\mathrm{Su}$ found an excuse to kick him out of her family for the benefit of Hung-chien, trying to show her tenderness and kindness to Hung-chien and rouse his courage for love. Such an act conforms to the tact maxim and then obtains much gratitude of the other (A: You're too kind to me.).

In dialogue 2, "that girl" means Miss Tang. Miss $\mathrm{Su}$ was displeased at seeing Hung-chien's showing off in front of Miss Tang, especially his disappointing look when she mentioned Miss Tang's boyfriends. She was filled with a twinge of jealousy then. Having realized that he offended Miss Su's face for his too much attention on Miss Tang, Hungchien praised and complimented her in positive language, so as to better their ties and build up their friendship. 


\section{A: Fang Hung-chien}

B: Miss Tang

A: That won't do. When you call me 'senior,' I feel like a prehistoric relic...It's my misfortune to have been born too early. Not being lucky enough to go to school at the same time you did is something I regret.

B: Mr. Fang, you are too concerned with insignificant details. Forgive me. I'll first retract the word 'elder'.

While Miss Tang called him "elder schoolmate", Hung-chien showed his protest by demoting himself but promoting his counterpart instead of blaming Miss Tang. He utilized her mentality by suffering certain losses. What he wanted was to impress the cute and charming girl and shorten the age gap between them, which is in accordance with the generosity maxim of self loss. Thus Miss Tang agreed to retract the word "elder".

\subsection{Approbation Maxim}

\section{Dialogue 1}

\section{A: Miss Pao $\quad$ B: Miss Su}

A: You're sure up early. On a hot day like this, I prefer to loaf in bed...I was sleeping like a log.

B: Then you're the precious little darling asleep in the cradle. Now, isn't that cute.

A: You! Su Tung-po's little sister, the girl genius!

Dialogue 2

Hung-chien: Women are natural political animals...For a woman to study political science is really developing the innate through the acquired; it is as superfluous as adding flowers to embroidery.

In the first dialogue, noticing that Miss Pao felt a little pity for her sleeping late, Miss Su compared her to the tender and cute baby in the cradle, giving her a sense of mental enjoyment and pleasure. In return, Miss Pao likened Miss Su to the talented and wise woman, Su Hsiao-mei. All these comparisons made them both feel softer and happier. In Dialogue 2, When Hung-chien made a bad shot of Miss Tang's major, Miss T'ang told him that political science was actually a quite common subject. Hungchien tried his best to flatter her so as to avoid repulsion and displeasure and saving her face as best as possible.

\subsection{Modesty Maxim}

Hung-chien: Now that you've clapped at the start, if my lecture can't live up to such enthusiastic applause, it'll put me in the embarrassing position of having been paid without being able to deliver the goods.
Hung-chien dreaded giving lecture and was about to turn it down at first. Whereas his father had already accepted the invitation in the hope of seeing his son win praises for his knowledge and scholarship. With so many curious eyes on him, Hung-chien could only remember a few vague facts and forgot the rest of the speech out of nervousness. After a round of applause, he braced himself and opened his remarks by-putting himself down and lowering the expectation of the audience in witty and humorous language, in order to ease his tension and embarrassment. This prologue produced, by contrast, a strong attractiveness to the audience.

\subsection{Agreement Maxim}

\section{A: Fang Hung-chien $\quad$ B: Miss Su}

A: When I saw that item in the paper, first I thought of you, of how you would ridicule and despise me. I even got into a big row with my socalled father-in-law about the whole news release.

B: What for? Why naturally all those insufferable, vulgar businessmen expect a return on their money. You can't expect them to understand that true learning doesn't depend on a degree. Why quarrel with him?

Hung-chien felt so ashamed and wished to hide somewhere, when he knew that Miss Su had heard of the news item (purchasing a fake degree and accepting an adoptive relative) in Shanghai Paper. He worried that she would look down upon him, which would have a bad effect on their ongoing relationship. According to research findings, when the interests of the interactants are consistent, the sufferings of one side can be easily felt and accepted by the opposite party. Miss $\mathrm{Su}$ was just using this "seek agreement" mentality to comfort Hung-chien by attacking those vulgar businessmen. Through reducing differences but increasing agreement, Miss Su maintained Hung-chien's quality face, shortened the mental gap between themselves, and met the mental and communicative expectation of Hungchien. (A: When you put it that way, I don't feel so guilty anymore. I should have come and told you everything earlier. You are so understanding!)

\subsection{Sympathy Maxim}

\section{A: Hung-chien's father-in-law \\ B: Hung-chien 's mother-in-law}

A: I knew you wouldn't (have girlfriend). Your father gave you a good upbringing. You're a gentleman and not the type to get mixed up with any free courtship.

B: Hung-chien is such a simple-hearted soul; he won't be able to find a girl for himself. Let me watch out and make a match for him. 
Hung-chien's fiancé had died five years before his return to his hometown. When Hung-chien's mother-in-law came up with the issue of marriage, asking if he had a girlfriend; Hung-chien quickly replied no. The couple simply comforted and guided him to free his burden and not be self-abased with kind and sympathetic words. Here Hung-chien could deeply feel the understanding and consideration conveyed by the couple.

\section{CONCLUSION}

Brown and Levinson's face-saving theory is mostly symbolized in Chien Chung-shu's Fortress Besieged. According to Brown and Levinson, every model person has two kinds of special characteristics: face and rationality. Therefore, to keep face, we must actualize some language actions in accordance with certain social conventions in communications and take some politeness redressive strategies to farthest decrease the degree of FTAs when some FTAs are unavoidable. Meanwhile, the main idea of Leech's politeness maxims is the least benefit of self, the most of other; and the most cost of self, the least of other. Since the goal of communication is to promote harmony between human beings, people need to use indirect directives and choose politeness principles tactfully, showing their respect for the other and promoting successful interchange.

However, despite its recognized importance and omnipotence in day-to-day discourse, politeness has proved enormously difficult to describe and explain its operation (Gao 2002). According to Archer (2012), politeness and impoliteness are shaped by the context-of-utterance and/or the roles of relationships between the participants. Politeness maxims, for example, may vary with different factors like age, gender, nationality, rank of position, and social distance between the two speakers, etc. They can also have a significant effect on how we interpret the politeness and how we apply it. When Chinese people and Westerners receive the same praise, for instance, the former like to say "no, no" in a humble way for their modest, euphemistic and implicit emotion, while the latter tend to accept it and show their appreciation for the kindness resulting from their frank, open and direct expression of feelings.

So "while admitting the universality of politeness, we must realize its relativity. That's to say, there is differences in expressing politeness and in judging the criterion of politeness in different cultures."(He 2000) We need to have a better understanding and mastery of language strategies and principles to guide our interactional acts. (Lu 2007) In considering politeness at this level, a deeper study and exploration of politeness and its application in different situations is quite essential for coordinating interpersonal relationship and promoting harmonious communications between people.

\section{REFERENCES}

[1] Archer, D. Aijmer, K \& Wichmann, A. 2012. Pragmatics: An Advanced Resource Book for Students. Routledge: Taylor \& Francis Group.

[2] Brown, P. \& Levinson, S. 1978. Politeness. Cambridge: Cambridge University Press.

[3] Brown, P. \& Levinson, S. 1987. Politeness: Some Universals in Language Usage. Cambridge: Cambridge University Press.

[4] Chien Chung-shu. 2001. Fortress Besieged. Beijing: Beijing People's Press.

[5] Gao, X. 2002. Perspectives on Politeness in English and Chinese Cultures. Chongqing: Master Degree Thesis of Southwest Normal University.

[6] He, Z. X. 2000. A New Introduction to Pragmatics. Shanghai: Shanghai Foreign Language Education Press.

[7] Lakoff, R. 1990. Talking Power: the Politics of Language in Our Lives. New York: Basic Books.

[8] Leech, G.. 1983. Principles of Pragmatics. London: Longman.

[9] Li, C.T. \& Ran, Y. P. 2014. Mock Politeness in Interaction and Its Pragmatic Features. Journal of Foreign Languages. 37(2):50.

[10] Lu, M. 2007. An analysis of Chinese Politeness Principle. Academics in China. 124(3): 233.

[11] Yule, G. 2000. Pragmatics. Shanghai: Shanghai Foreign Language Education Press. 